\title{
PHYTOCHEMICAL SCREENING OF DIFFERENT CRATAEGUS OXYACANTHA EXTRACTS
}

\author{
NELI-KINGA OLAH ${ }^{a, b}$, RAMONA BURTESCU $^{b}$, SORINA PETRESCU ${ }^{b}$, \\ ANDREEA BRAȘOVAN ${ }^{c}$, ELISABETA CHIȘE ${ }^{a}$, SIMONA CODRUȚA \\ AURORA COBZAC ${ }^{\mathrm{d}}{ }^{*}$, DANIELA HANGANU ${ }^{*}$
}

\begin{abstract}
Crataegus oxyacantha L., the hawthorn, is a well-known medicinal plant with cardiotonic effect. This paper presents a complex phytochemical screening of polyphenols profile, both qualitatively and quantitatively, in three different extracts obtained from fresh berries, flowers with leaves and young shoots. There were used spectral (UV-Vis) and chromatographic (TLC, HPLC) methods to evaluate the total flavonoids, total phenolic acids and qualitative polyphenols profile of the extracts. The antioxidant capacity was evaluated by DPPH, FRAP and NO radical inhibition methods, by UV-Vis spectrophotometry. The total flavonoid content expressed in rutoside ranges from 0.49 to 1.33 $\mathrm{mg} / \mathrm{ml}$, the total phenolic acids expressed in caffeic acid from 0.02 to 0.10 $\mathrm{mg} / \mathrm{ml}$, the most concentrated being the berries extract. In flowers with leaves extract can be identified and quantified a special flavonoid, the vitexine, 0.37 $\mathrm{mg} / \mathrm{ml}$. All three extracts present important antioxidant activity, both on ROS and RNS species. By FRAP method the berries extract was determined as most powerful, having also the best inhibition effect on NO radicals. The DPPH method indicates the special young shoots extract, used in gemmotherapy, as being the most powerful, with significant inhibiting effect on NO radicals. This indicates that the young shoots gemmotherapic extract is a good candidate for a powerful therapeutic tool.
\end{abstract}

Keywords: Crataegus oxyacantha extracts, spectral assays, TLC, HPLC$D A D$, antioxidant capacity

a "Vasile Goldis" Western University of Arad, Faculty of Pharmacy, 86 L. Rebreanu str., Arad, Romania

${ }^{b}$ SC PlantExtrakt SRL, 407059 Rădaia. Cluj, Romania

${ }^{c}$ Babeş-Bolyai University of Cluj-Napoca, 1 Kogălniceanu Str., Cluj-Napoca, Romania

${ }^{d}$ Babeş-Bolyai University of Cluj-Napoca, Faculty of Chemistry and Chemical Engineering, 11 Arany Janos Str., Cluj-Napoca, Romania

*Correspondent authors: danahcluj@gmail.com, csimona@chem.ubbcluj.ro

e "Iuliu Hațieganu" University of Medicine and Pharmacy from Cluj-Napoca, Faculty of Pharmacy, 8 Victor Babeș str., Cluj-Napoca, Romania 


\section{INTRODUCTION}

Crataegus oxyacantha L. or Crataegus monogyna Jacq., the hawthorn, is one of the most known and used vegetal remedy for different cardiovascular disturbances. It belongs to Rosaceae family, being a shrub with white flowers grouped in corymb and intensive red berries as fruits with one stony seed. Traditionally, for medicinal purposes are used the flowers with leaves respectively the fruits. The vegetal material or the extracts, obtained both from dried or fresh plants, are standardized in flavonoids or $/$ and oligomeric proanthocyanidines [1-3].

The phytochemical researches using different spectral and chromatographic methods identified in the hawthorn oligomeric proanthocyanidines, flavonoids of flavone and flavonole types, phenolic acids, triterpenes, fatty acids, sterols $[3,4]$. The studies were conducted on vegetal materials, but also on hydroalcoholic extracts. The alcoholic extracts from berries and flowers with leaves contain vitexine, hyperoside, rutoside, luteoline, apigenin and different vitexine, luteoline and apigenin derivatives from class of flavonoids; catechine and epicatechine derivatives from oligomeric proanthocyanidines; ursolic, oleanolic and crategolic acids from class of triterpenes; chlorogenic and caffeic acids from class of phenolic acids, respectively amines. The quantitative analyses identified $14.3 \mu \mathrm{g} / \mathrm{g}$ respectively $1.65 \mu \mathrm{g} / \mathrm{g}$ flavonols in the leaves respectively berries and 5.11 $\mathrm{mg} / \mathrm{g}$ oligomeric proanthocyanidines into berries [5-7]. Another study evidenced in berries extracts $3.54 \%$ phenolics expressed in gallic acid, $0.18 \%$ flavonoids aglyca, $0.14 \%$ hyperoside and $0.44 \%$ oligomeric proanthocyanidines [4]. A comparative study performed on tinctures obtained from dried and fresh flowers with leaves highlight that the freshly processed vegetal material contains higher quantity of oligomeric proanthocyanidines, with reduced stability into alcoholic extracts and with 1.5 times less flavonoids like the extract obtained from dried vegetal product [8]. A recent study evidenced in flowers and leaves originary from Pakistan a lot of sterols and triterpenes: $\beta$-sitosterol-3-O- $\beta$-D-glucopyranoside, lupeol, $\beta$ sitosterol, betuline, betulinic acid, oleanolic acid and from flavonoids class the chrysine. From these compounds the sitosterol derivative was linked to the anticholinesterase effect with potential benefit into the improvement of Alzheimer disease's symptoms [9].

Due by the high content in polyphenols the hawthorn has high antioxidant capacity correlated also with cardioprotector and antiinflammatory effects $[3,9,10]$. The antioxidant effect is expressed in the improvement and activation of the antioxidant enzymes status, like superoxide dismutase, catalase, glutathione peroxidase, glutathione, respectively in the inhibition of lipids peroxidation. Studies revealed, by 
DPPH method, that the berries have a 1000 times more elevated antioxidant capacity than the quercetine, a powerful antioxidant flavonoid, while the leaves have 10 times more elevated this effect. The antioxidant and lipid lowering effects are due mainly by the high content in flavonoids [3,5,11-12]. It was proved that the anti-inflammatory effect is due by inhibition of different enzymes and cytokines, like COX2, $\alpha \mathrm{TNF}$ IL-1 $\beta$, IL-6 and iNOS [5].

At cardiovascular level were proved the beneficial effects in heart failure, stage I and II according to NYHA, angina pectoris, hypertension, mild arrhythmia and atherosclerosis $[3,13,14]$. The hawthorn berries and flowers with leaves lower the blood pressure, dilating the vessels, have endothelium protector effect, decrease the migration and proliferation of smooth muscle cells, protect in case of ischemia and determine a better use of the oxygen by the myocardium due by its positive inotropic and negative chronotropic activity, by improving the coronary stream and by inhibition of the angiotensin converting enzyme respectively the phosphodiesterase. Additionally have anxiolytic, antihyperlipidic, antihyperglycemic, immunomodulating and antimutagenic effects $[3,5,15]$. The flavonoids and oligomeric proanthocyanidines are responsible for the inhibition of angiotensin converting enzyme [16].

Clinical trials proved the efficacy of hawthorn products in case of stable angina pectoris by lowering the intercellular adhesive molecules, like ICAM-1 and the E-selectine, responsible by the coronary atherosclerosis development [17]. A randomized double blind clinical trial performed on a tincture obtained from fresh hawthorn berries evidenced its efficacy in stage II hearth failure, in long term administration [18].

The hawthorn berries and flowers with leaves have a good antimicrobial activity on Pseudomonas aeruginosa and mild effect on Escherichia coli [11].

Local traditions use hawthorn also in case of digestive disturbances, dyspnea, respectively in case of renal lithiasis $[5,15]$

The hawthorn is used in therapy mostly as hydroalcoholic extracts or dry extracts, on tablets or capsules form. Recent phytochemical, pharmacological and clinical studies are performed on extracts obtained from fresh plants. The use of fresh plants is characteristic for the new phytotherapy branches, like gemmotherapy is, that use the part of plants containing meristematic tissues. Because all type, classical and modern, extracts from hawthorn are used mainly as cardiotonic it worth to study comparatively to determine the differences in phytochemical profile that can indicate some differences also in efficacy.

This paper presents a comparative study of phytochemical profile of the tinctures obtained from fresh hawthorn berries and fresh hawthorn flowers with leaves respectively the glycerol macerate obtained from fresh hawthorn young shoots, used in gemmotherapy, performed by different spectral and chromatographic methods. 


\section{RESULTS AND DISCUSSION}

In figures 1 and 2 are presented the calibration curve of rutoside respectively of caffeic acid used for the determination of total flavonoids respectively total phenolic acids content.

In figures 3-6 are presented the TLC respectively the HPLC chromatograms of the three studied extracts.

In figure 7 is presented the calibration curve for vitexine used for determination of the content by HPLC.

In tables 1 and 2 are presented the obtained results.

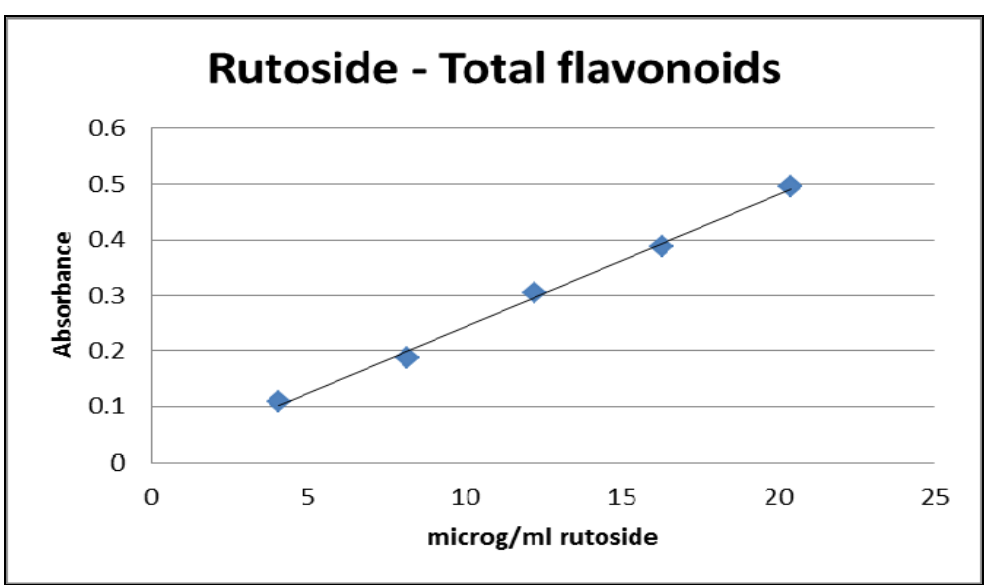

Figure 1. The calibration curve of rutoside for total flavonoids content determination Absorbance $=0.024 \times$ Conc $[\mu \mathrm{g} / \mathrm{ml}]+0.0031 ; R^{2}=0.9970$

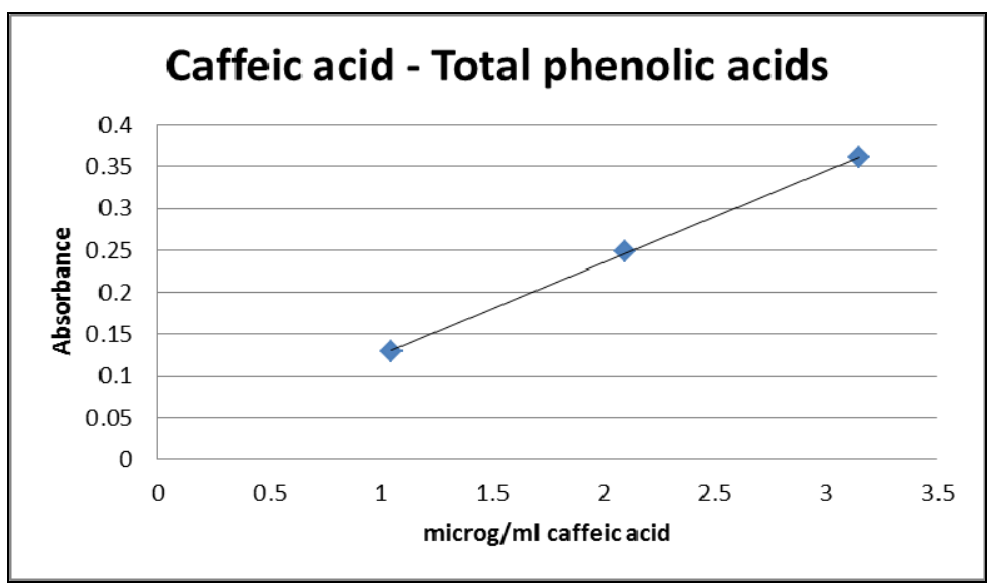

Figure 2. The calibration curve of caffeic acid for total phenolic acids content determination Absorbance $=0.1098 \times$ Conc $[\mu \mathrm{g} / \mathrm{ml}]+0.0157 ; \mathrm{R}^{2}=0.9997$ 
PHYTOCHEMICAL SCREENING OF DIFFERENT CRATAEGUS OXYACANTHA EXTRACTS

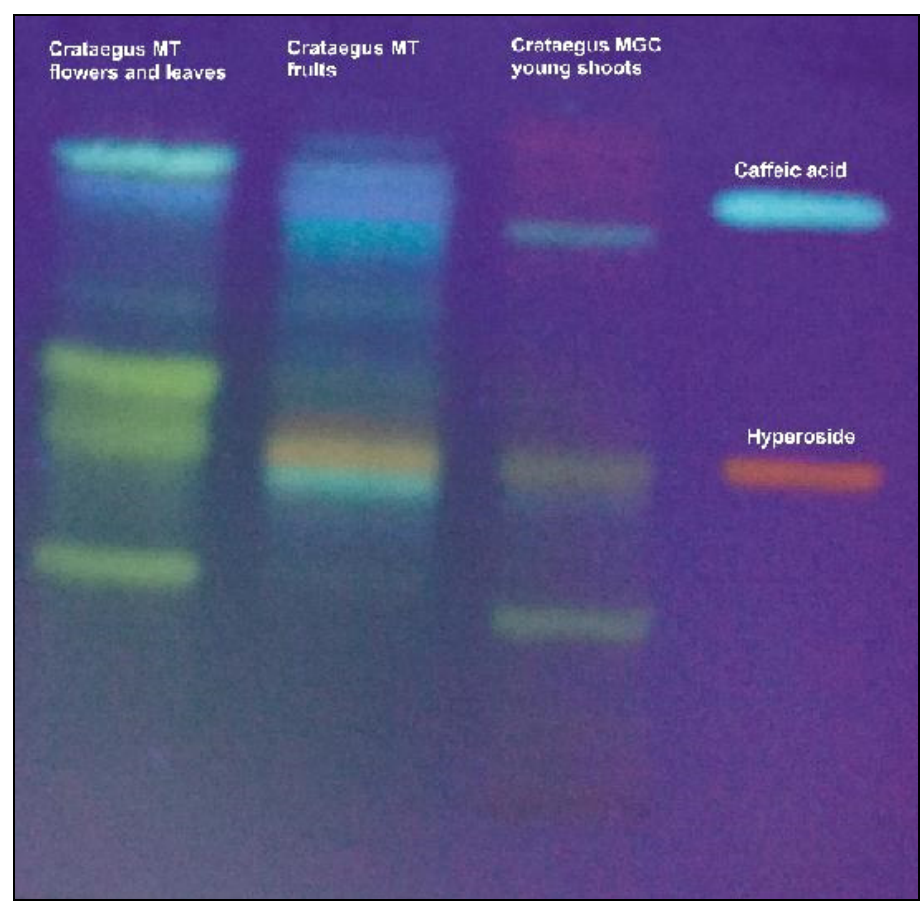

Figure 3. The TLC chromatogram in fluorescence at $365 \mathrm{~nm}$.

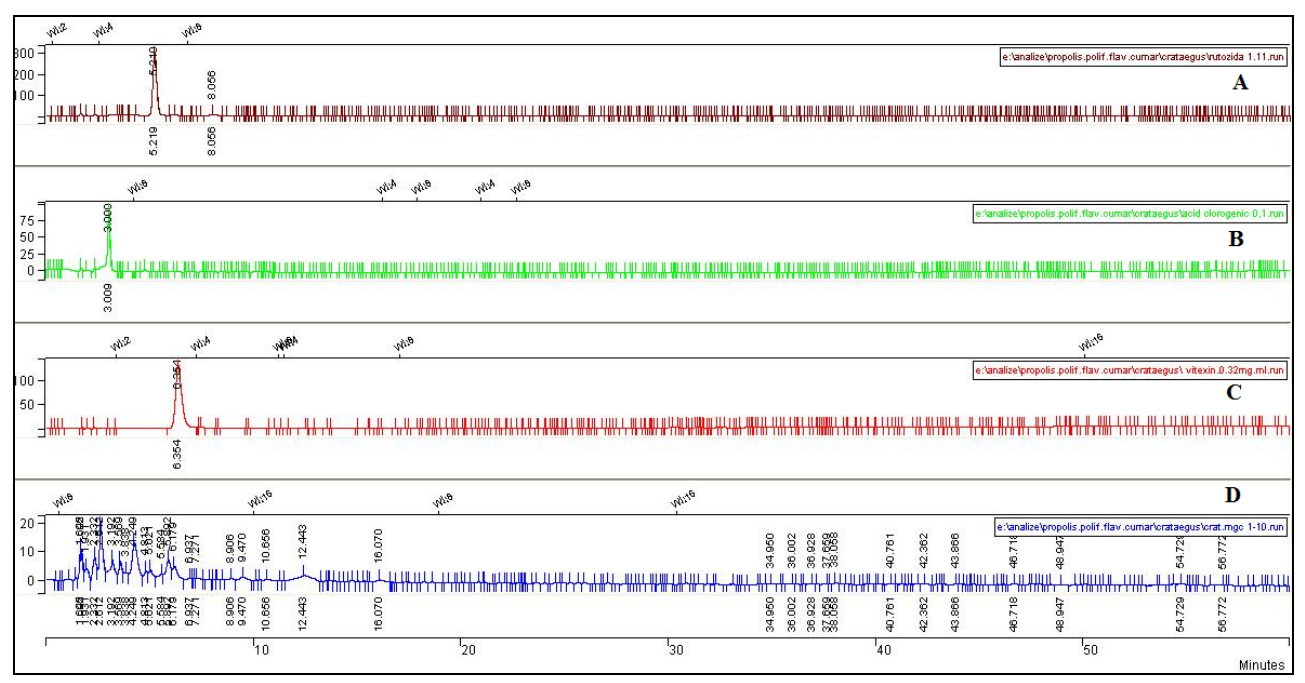

Figure 4. The HPLC chromatogram for glycerol macerate from hawthorn young shoots.

A -rutoside, B - chlorogenic acid, C - vitexine, D - extract 
N.-K. OLAH, R. BURTESCU, S. PETRESCU, A. BRAȘOVAN, E. CHIȘE, S. C. A. COBZAC, D. HANGANU

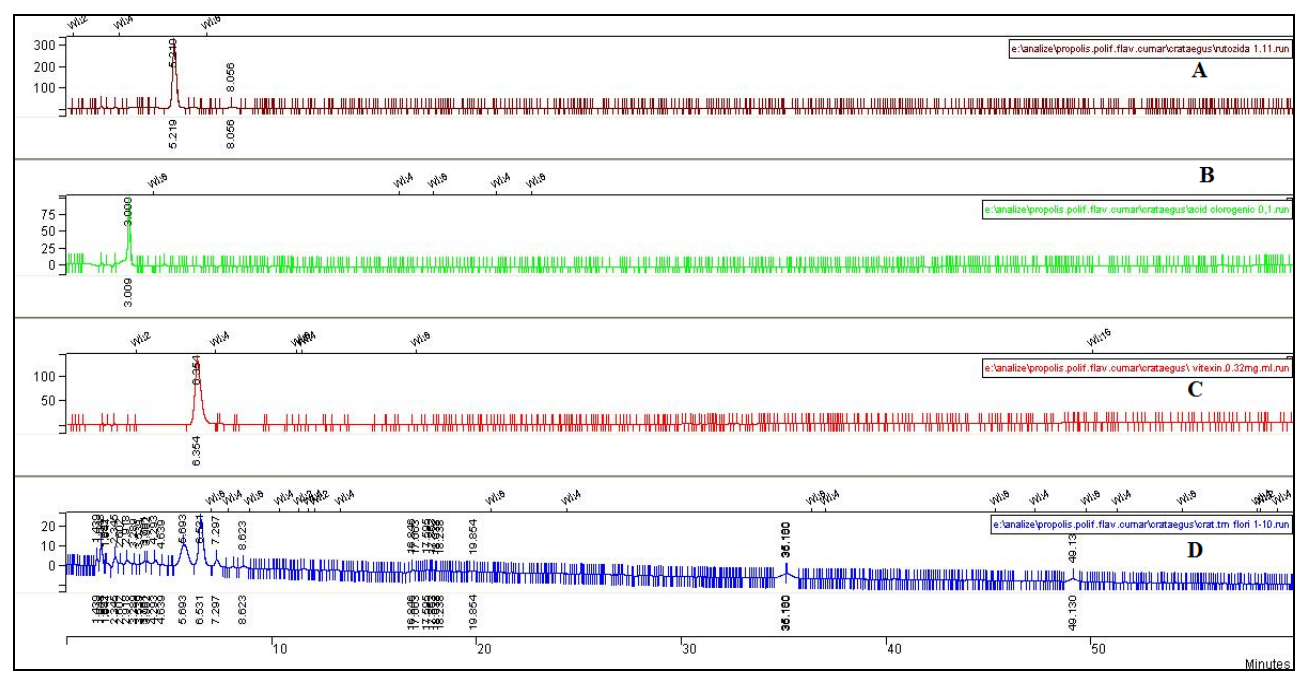

Figure 5. The HPLC chromatogram for hydroalcoholic extract from hawthorn flowers and leaves.

A -rutoside, B - chlorogenic acid, C - vitexine, D - extract

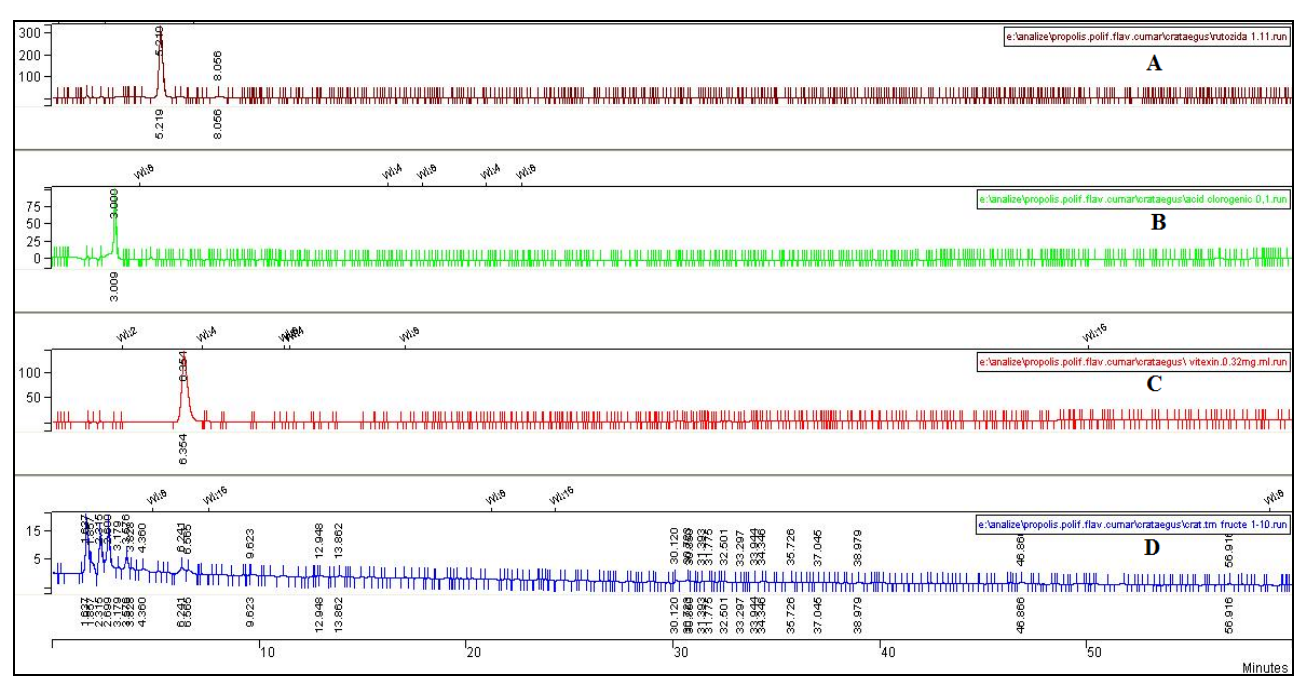

Figure 6. The HPLC chromatogram for hydroalcoholic extract from hawthorn berries.

A -rutoside, B - chlorogenic acid, C - vitexine, D - extract 


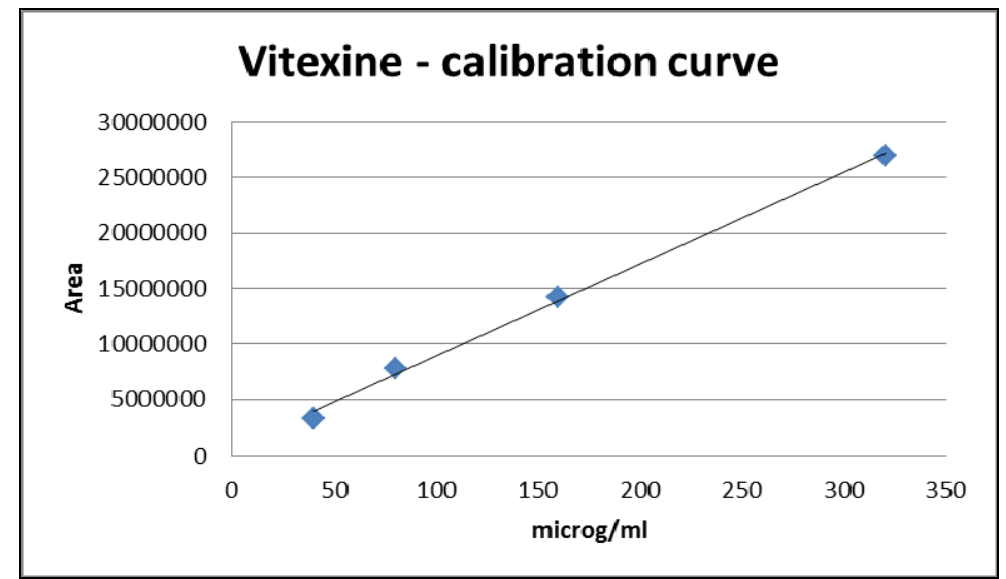

Figure 7. The calibration curve for dosing the vitexine by HPLC Area $=83194 \times$ Conc $[\mu \mathrm{g} / \mathrm{ml}]+585207 ; R^{2}=0.9977$

Table 1. The results from TLC and HPLC analyses

\begin{tabular}{|c|c|c|}
\hline Hawthorn extract from & $\begin{array}{c}\text { Number of compounds } \\
\text { separated by TLC }\end{array}$ & $\begin{array}{c}\text { Number of compounds } \\
\text { separated by HPLC }\end{array}$ \\
\hline Young shoots & $\begin{array}{c}6 \\
\text { (2 chlorophylls) }\end{array}$ & 16 \\
\hline Flowers with leaves & 6 & 11 \\
\hline Berries & 10 & 10 \\
\hline
\end{tabular}

Table 2. The quantitative results from spectral and chromatographic analyses

\begin{tabular}{|c|c|c|c|}
\hline $\begin{array}{c}\text { Hawthorn extract } \\
\text { from }\end{array}$ & $\begin{array}{c}\text { Total flavonoids } \\
\text { expressed in } \\
\text { rutoside, } \mathbf{~ m g / m l}\end{array}$ & $\begin{array}{c}\text { Total phenolic acids } \\
\text { expressed in caffeic } \\
\text { acid, } \mathbf{~ m g / m l}\end{array}$ & $\begin{array}{c}\text { Vitexine content, } \\
\mathbf{m g} / \mathbf{m l}\end{array}$ \\
\hline Young shoots & $0.87 \pm 0.003$ & $0.07 \pm 0.001$ & - \\
\hline Flowers with leaves & $0.49 \pm 0.001$ & $0.02 \pm 0.001$ & $0.37 \pm 0.005$ \\
\hline Berries & $1.33 \pm 0.059$ & $0.10 \pm 0.002$ & - \\
\hline
\end{tabular}

The spectral analyses indicate that the highest concentration of polyphenols, flavonoids and phenolic acids are in berries tincture, and the lowest in the flowers with leaves extract. These are in correlation with the results obtained at TLC analysis where the flower with leaves extract show compounds with different yellow color. The quantitative spectral results can be correlated with those obtained by Tadic et al. in the berries extracts from Serbia [12].

The TLC analysis revealed the separation of 4 phenolic compounds in young shoots, 6 in flowers with leaves and 10 in berries. These compounds have yellow, orange-yellow, blue and greenish-blue fluorescence. The yellow 
and orange-yellow colors indicate flavonoids, while the blue and greenish-blue colors the phenolic acids. The separated active compounds profile is different at flowers with leaves extract comparing with the others. This extract present three intensive yellow band corresponding to flavonoids, while the other two extracts have a yellow, a blue, an orange-yellow and an orange band in the same positions. The orange band is present more intensively in the berries extract and could be interpreted as being hyperoside. There are similarities between the young shoots and berries extracts also in the presence of a blue band around the caffeic acid. Just in the young shoots extract can be observed the red bands characteristic for chlorophylls. The TLC analysis evidenced the similarities and also the differences in phytochemical profile of the different hawthorn vegetal materials respectively extracts from these parts, but the results are according with the provisions of pharmacopoeias monographs respectively with the known scientific references that highlights the presence of flavonoids and phenolic acids in this species $[1,2,19]$.

The HPLC analysis evidenced the same similarities and differences like were observed at TLC analysis. The number of separated compounds is similar in all extracts. From the berries and flowers with leaves extracts are separated 10 or 11 compounds, from young shoots 16 compounds. The table 3 shows the position of each separated compound and the maximum absorbance of their UV-Vis spectra.

It can be identified caffeic acid derivatives in young shoots extract at $1.65,2.60$ and 3.20 minutes based on absorption maximums and the shape of the UV-Vis spectra. The compound from 2.60 minutes could be chlorogenic acid according the UV-Vis spectra data, but is separated at 0.4 minutes difference in comparison with the standard. The compounds separated at $4.25,5.90,6.20$ and 9.50 could be flavonoids according the UV-Vis spectra shape and maximum absorption wavelengths. It could not be identified any of them as rutoside, neither the retention time, neither the maximum absorption wavelengths do not correspond.

In the flower with leaves extract can not be identified any caffeic acid derivatives, but the compounds separated at 5.70 and 6.50 minutes could be flavonoids. It can be identified the vitexine, separated at similar retention time and with similar shape and absorption maximums like the standard. This corresponds with those mentioned in scientific references [5]. This extract contains $0.37 \mathrm{mg} / \mathrm{ml}$ vitexine, representing $75.5 \%$ from total flavonoids.

The berries extracts contains possible flavonoids separated at 4.40, 6.20 respectively 6.60 minutes, but it could not be identified the rutoside. This is according with the references that mentioned the lower flavonoid content in fresh berries [8]. The higher total flavonoid content determined by spectral method using aluminum chloride could be explained by the possible interference of oligomeric proanthocyanidines. 
Table 3. The retention time and the UV-Vis absorption maxims of the separated compounds by HPLC

\begin{tabular}{|c|c|c|c|c|c|}
\hline \multicolumn{2}{|c|}{ Young shoots extract } & \multicolumn{2}{|c|}{ Flowers with leaves extract } & \multicolumn{2}{|c|}{ Berries extract } \\
\hline$t_{r}, \min$ & $\begin{array}{c}\text { UV-Vis } \\
\text { absorption } \\
\text { maxims, } \mathrm{nm}\end{array}$ & $\mathbf{t}_{\mathrm{r}}, \mathbf{m i n}$ & $\begin{array}{l}\text { UV-Vis absorption } \\
\text { maxims, } \mathrm{nm}\end{array}$ & $\mathbf{t}_{\mathrm{r}}, \min$ & $\begin{array}{c}\text { UV-Vis } \\
\text { absorption } \\
\text { maxims, nm }\end{array}$ \\
\hline 1.65 & $237+328$ & 1.65 & 234 & 1.65 & $233+280$ \\
\hline 2.30 & $233+293$ & 2.30 & 296 & 2.30 & 294 \\
\hline 2.60 & $238+325$ & 2.60 & $236+268+296$ & 2.70 & $263+298$ \\
\hline- & - & 2.90 & $234+263+298$ & - & - \\
\hline 3.20 & $234+328$ & - & - & 3.20 & $236+288$ \\
\hline 3.60 & 352 & 3.60 & $234+268+318$ & 3.60 & $234+308$ \\
\hline 4.25 & $267+343$ & 4.30 & $258+332$ & 4.40 & $236+271+349$ \\
\hline 5.00 & $236+268+346$ & - & - & - & - \\
\hline 5.90 & $260+357$ & 5.70 & $234+268+343$ & - & - \\
\hline 6.20 & $263+355$ & - & - & 6.20 & $265+359$ \\
\hline- & - & 6.50 & $268+343$ & 6.60 & $240+360$ \\
\hline 8.90 & 242 & - & - & - & - \\
\hline 9.50 & $238+357$ & - & - & 9.60 & 240 \\
\hline 10.70 & 243 & - & - & - & - \\
\hline 12.45 & $240+269+346$ & - & - & - & - \\
\hline - & - & - & - & 13.00 & 241 \\
\hline 16.00 & 242 & - & - & - & - \\
\hline 35.00 & 241 & 35.10 & $240+318$ & - & - \\
\hline 49.00 & $240+304+357$ & 49.10 & $240+268+310+356$ & & \\
\hline \multicolumn{2}{|c|}{ Chlorogenic acid } & \multicolumn{2}{|r|}{ Rutoside } & \multicolumn{2}{|c|}{ Vitexine } \\
\hline 3.00 & $239+325$ & 5.20 & $264+355$ & 6.20 & $267+344$ \\
\hline
\end{tabular}

The HPLC results are in concordance with the TLC and spectral results, explaining the difference in color of the flavonoids from flower and leaves due by the presence of vitexine that have a different structure like the rutoside or hyperoside (figure 8).

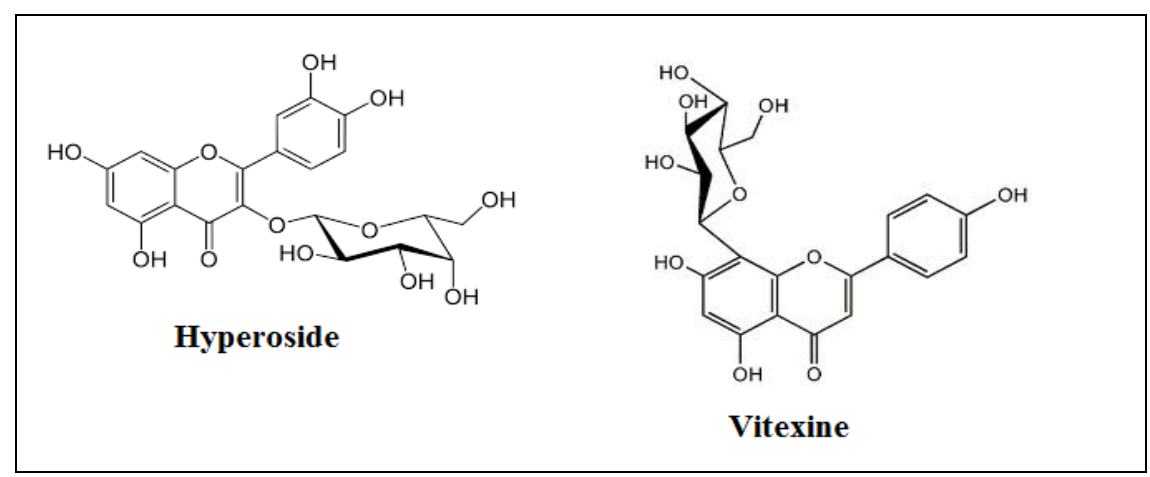

Figure 8. The structures of hyperoside and vitexine 
The antioxidant capacity evaluation results are presented in table 4 . In figure 9 are presented the extracts curve for $I_{50}$ determination by $D P P H$ method respectively in figure 10 the Trolox calibration curve for FRAP method.

Table 4. The results of antioxidant capacity evaluation

\begin{tabular}{|c|c|c|c|}
\hline Extracts from & DPPH, $\mathbf{I C}_{\mathbf{5 0}}, \boldsymbol{\mu l}$ & $\begin{array}{c}\text { FRAP, } \\
\mu \mathrm{M} \text { TE } / \mathbf{1 0 0} \mathbf{~ m l} \\
\text { extract }\end{array}$ & $\begin{array}{c}\text { NO radical } \\
\text { inhibition, \% }\end{array}$ \\
\hline Young shoots & 6 & $848 \pm 1.12$ & 70.3 \\
\hline Flowers with leaves & 80 & $278 \pm 0.50$ & 65.5 \\
\hline Berries & 93 & $1255 \pm 3.28$ & 74.3 \\
\hline Trolox (standard) & $50 \mu \mathrm{g}$ & - & - \\
\hline
\end{tabular}

The results show a good correlation of the antioxidant activity determined by FRAP and the content in polyphenols determined by spectral methods (see figure 11). The DPPH method show a better antioxidant activity of young shoots extract, the other two extracts having similar values and approximately 1.5-2 times less than the standard trolox. These results are according to that obtained by Benmalek et al., reference that mention a more effective antioxidant capacity of berries extract in comparison with the leaves or flowers extracts [7].

The results obtained with DPPH method can not be correlated with the extracts' polyphenols content. This leads us to conclude that the different hawthorn extracts will contain different type of antioxidant compounds which will act specifically on different radicals. This explains also the different results by different evaluation methods. On other hand to the antioxidant effect could contribute also other compounds types near polyphenols.

The DPPH evaluation shows that the young shoots extract is more powerful, even that the polyphenols content is lower as the berries extract and the extraction ratio, 1:20, lead to a more diluted extract like the berries' is. This result indicates that the young shoot hawthorn extract used in gemmotherapy could have a more powerful effect like the classical hawthorn extracts.

All three extracts have important NO radical inhibition effect. The value are similar, the most effective being the berries and young shoots extracts. Even that the values are similar, there is a concordance between the NO radical inhibition and the extracts polyphenols content (see figure 11). This explain the beneficial effect of the hawthorn extracts on endothelium, by inhibiting the transformation of endothelium factor NO into radicals and the damaging of vessels wall. 
PHYTOCHEMICAL SCREENING OF DIFFERENT CRATAEGUS OXYACANTHA EXTRACTS

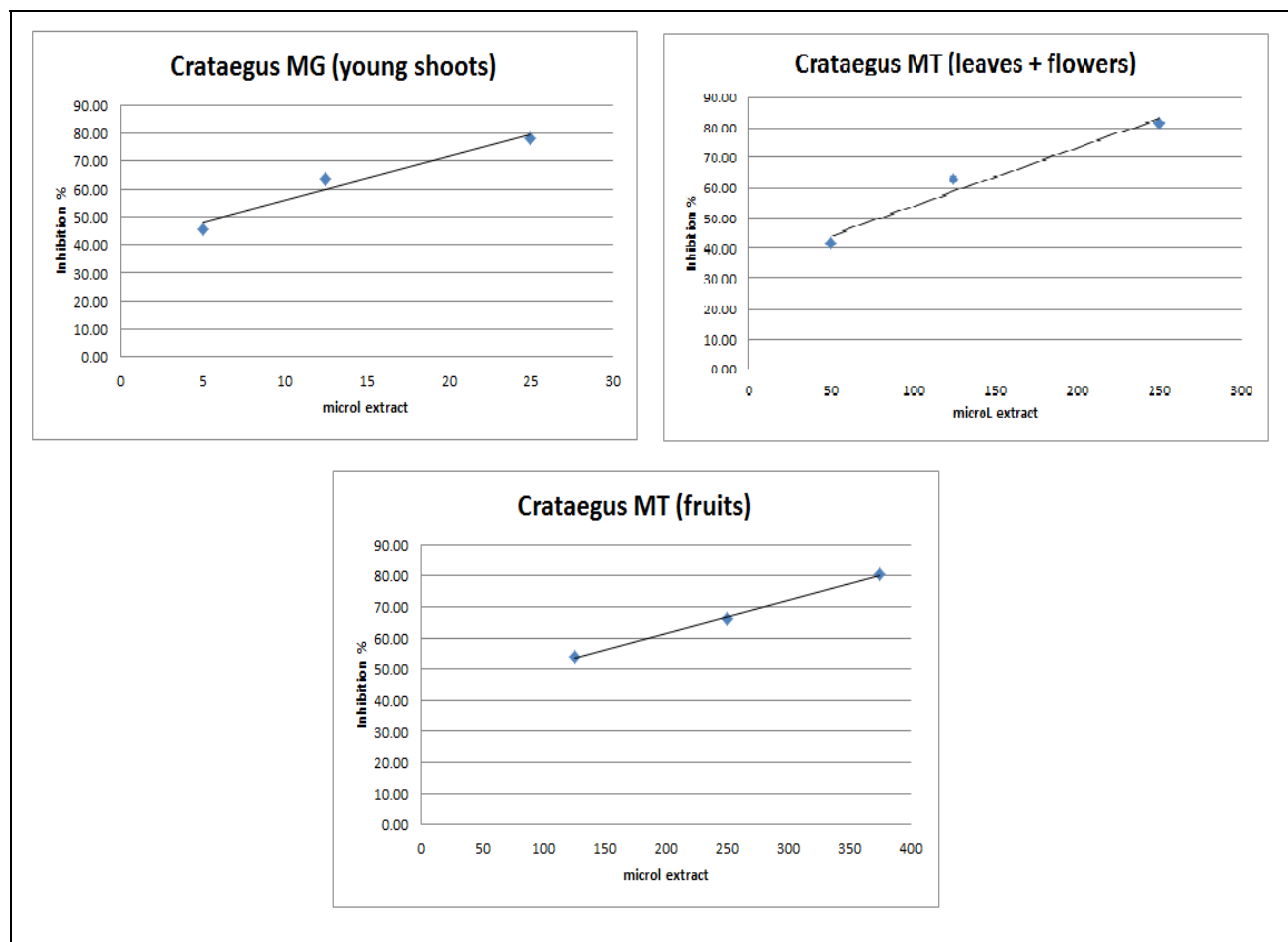

Figure 9. The inhibition curves for determination of $\mathrm{IC}_{50}$ by DPPH method; Young shoots: $\mathrm{I} \%=1.5774 \times$ Conc $[\mu \mid]+40.164 ; R^{2}=0.9619$; Flowers with leaves: $I \%=0.1943$ Conc $[\mu l]+34.461 ; R^{2}=0.9657 ;$ Berries: $1 \%=0.1067 \times$ Conc $[\mu l]+40.079 ; R^{2}=0.9989$

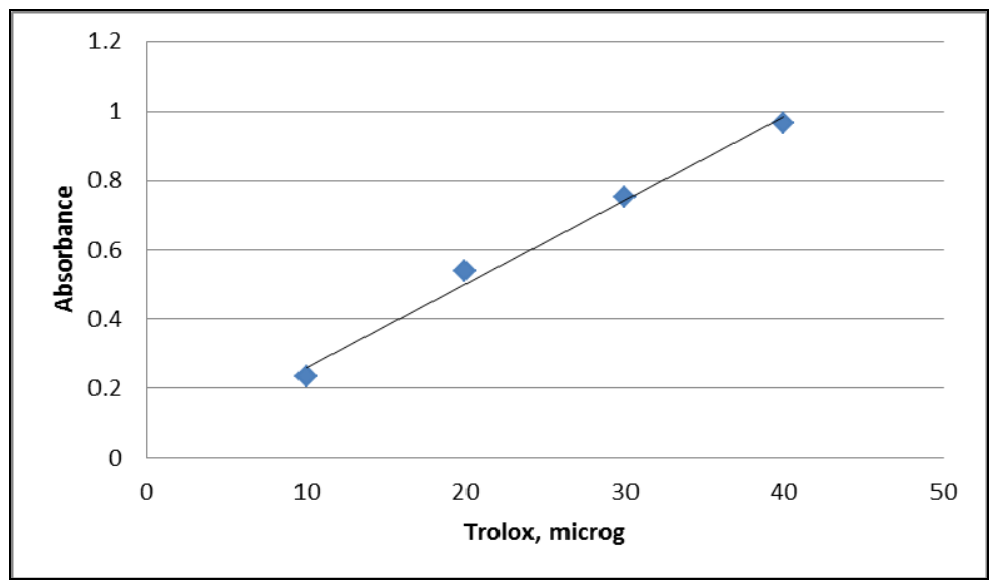

Figure 10. The calibration curve for Trolox by FRAP method 


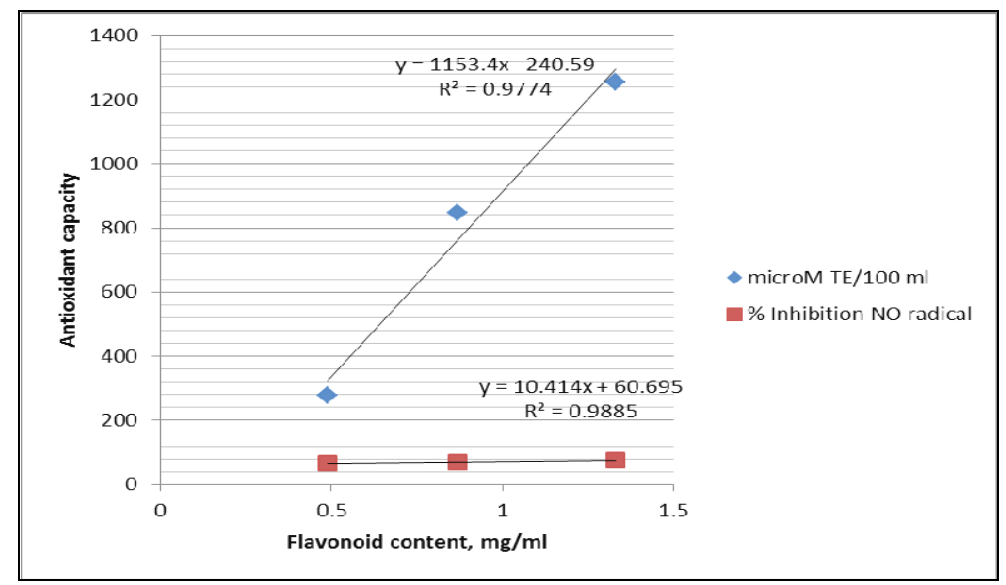

Figure 11. The correlation curves of antioxidant capacity with total flavonoid content

\section{CONCLUSIONS}

This paper highlights the differences and the similitudes between the phytochemical profiles of different hawthorn vegetal materials respectively extracts. It can be observed a difference regarding the polyphenols types contained by flowers with leaves in comparison with the berries and young shoots. This will lead to an efficacy difference sustained also by the antioxidant capacity evaluations.

The berries extract was observed to have the highest concentration in polyphenols with important antioxidant effect, both on reactive oxygen species (ROS) and reactive nitrogen species (RNS).

In this paper was presented for first time a complex phytochemical analysis of young shoots hawthorn extract, used in gemmotherapy, that proved to have a similar polyphenols profile like the berries extract, the most used in cardiovascular diseases, but in less concentration, with comparative or higher antioxidant activity with berries extract, both on ROS and RNS. These results lead us to conclude that the young shoots extract, with its complete phytochemical profile, including also the polyphenols, can be therapeutically more valuable as other hawthorn extracts, obtained from other parts of this specie. 


\section{EXPERIMENTAL SECTION}

\section{Materials, reagents and apparatus}

Crataegus oxyacantha L. young shoots, flowers with leaves and berries were collected from wild flora, in the woods near Cluj, in the springtime and autumn of year 2016. The fresh vegetal material was immediately processed after the collection. A voucher specimen was sampled, retained in herbarium, each time and the botanical identification was performed by the specialists from PlantExtrakt quality control laboratories.

The extracts were obtained according to provision of European and German Homeopathic Pharmacopoeias. There were obtained on GMP certified production flow mother tinctures from berries and flowers with leaves using $90 \%$ vol. ethanol, the extraction ratio being 1:0.75 (plantsolvent) respectively glycerol macerate from young shoots using $96 \%$ vol. ethanol $-100 \%$ glycerol mixture (1:1), the extraction ratio being 1:20 (dry part of the plant - solvent). The extraction was made at cold, by maceration 10-20 days, with daily mixing followed by pressing and filtering $[1,19]$.

The silicagel plate (Kiselgel $F_{254}$ ) was purchased from- Merck, (Germany). The HPLC column, type Luna $5 \mu \mathrm{m}$ C18 (2) 100 A of $150 \times 4.6$ $\mathrm{mm}$ was purchased from Phenomenex, USA. The Sil-C18 SPE columns were purchased from Merck, Germany.

The Teflon Millex filters were purchased from Merck-Millipore, USA.

Solvents and reagents: sodium acetate, aluminum chloride, methanol, sodium carbonate, sodium tungstenate, phosphoric acid, ferric chloride, TPTZ, DPPH, hydrochloric acid, sodium nitroprusside, sodium phosphate, sulfanilamide, N-1-naphtylethylenediamine, ethyl acetate, ethylmethyl ketone, formic acid and acetonitrile was supplied from Merck (Germany); PEG 400 was obtained from Roth, (Germany); diphenylboric acid aminoethyl ester was supplied from LGC (Germany).

The standards: rutoside, caffeic acid and trolox supplied from Merck (Germany), hyperoside, vitexine and chlorogenic acid were obtained from Phytolab (Germany).

Apparatus: Cintra 101 UV-Vis spectrophotometer, GBC Australia; Varian Prostar HPLC system with quaternary pump, autosampler and DAD detector, Varian USA.

\section{Assay for total flavonoid content determination [20]}

Samples: $1 \mathrm{ml}$ from each extract was mixed with $5 \mathrm{ml}$ of $10 \%$ sodium acetate and $3 \mathrm{ml}$ of $2.5 \%$ aluminum chloride. These mixtures were filled with methanol until $25 \mathrm{ml}$. 
Blank: $1 \mathrm{ml}$ from each extract was mixed with $8 \mathrm{ml}$ of water and filled to $25 \mathrm{ml}$ with methanol.

After 15 minutes the samples were read at $430 \mathrm{~nm}$. There were made 3 determinations and at every determination were made 3 repeated readings. The results are the average of the 3 determinations.

In the same conditions were built a calibration curve in rutoside, using solutions in methanol with a concentration of 4.08 to $20.4 \mu \mathrm{g} / \mathrm{ml}$.

\section{Assay for total phenolic acids content determination [21]}

Samples: $1 \mathrm{ml}$ from each extract was mixed with $0,5 \mathrm{ml}$ of phosphotungstenic reagent and filled with $15 \%$ sodium carbonate until $25 \mathrm{ml}$.

Blank: $1 \mathrm{ml}$ from each extract was filled to $25 \mathrm{ml}$ with $15 \%$ sodium carbonate.

After 2 minutes the samples were read at $715 \mathrm{~nm}$. There were made 3 determinations and at every determination were made 3 repeated readings. The results are the average of the 3 determinations.

In the same conditions were built a calibration curve in caffeic acid, using solutions in methanol with a concentration of 1.05 to $3.15 \mu \mathrm{g} / \mathrm{ml}$.

\section{Antioxidant capacity determination by DPPH method [22]}

Samples - berries extract: $0.25 ; 0.50$ respectively $0.75 \mathrm{ml}$ of extracts were diluted with methanol at $10 \mathrm{ml}$. From each solution an aliquot of $5 \mathrm{ml}$ was mixed with $5 \mathrm{ml}$ of DPPH reagent, then all were maintained at $40^{\circ} \mathrm{C} 30$ minutes.

Samples - flowers with leaves extract: $0.10 ; 0.25$ respectively 0.50 $\mathrm{ml}$ of extracts were diluted with methanol at $10 \mathrm{ml}$. From each solution an aliquot of $5 \mathrm{ml}$ was mixed with $5 \mathrm{ml}$ of DPPH reagent, then all were maintained at $40^{\circ} \mathrm{C} 30$ minutes.

Samples - young shoot extract: $1 \mathrm{ml}$ of extract was diluted with methanol at $10 \mathrm{ml}$, then aliquots of $0.25 ; 0.50$ respectively $0.75 \mathrm{ml}$ were diluted with methanol at $10 \mathrm{ml}$. From each solution an aliquot of $5 \mathrm{ml}$ was mixed with 5 $\mathrm{ml}$ of DPPH reagent, then all were maintained at $40^{\circ} \mathrm{C} 30$ minutes.

Control: $5 \mathrm{ml}$ methanol mixed with $5 \mathrm{ml}$ of DPPH reagent, maintained at $40^{\circ} \mathrm{C} 30$ minutes.

Blank: methanol.

The samples were read at $517 \mathrm{~nm}$. There were made 3 determinations and at every determination were made 3 repeated readings. The results are the average of the 3 determinations. 
For each sample was determined the inhibition percentage using the following formula:

$$
\mathrm{I} \%=\left(\mathrm{A}_{\text {control }}-\mathrm{A}_{\text {sample }}\right)^{* 100 / \mathrm{A}_{\text {control }}}
$$

For each extract was built a curve and from its equation was determined the $\mathrm{IC}_{50}$, meaning the quantity of extract that will neutralize 50 $\%$ of radicals.

\section{Antioxidant capacity determination by FRAP method [22]}

Samples: $0.50 \mathrm{ml}$ of each extract was diluted with methanol at 10 $\mathrm{ml}$. From each solution an aliquot of $0.2 \mathrm{ml}$ was mixed with $0.6 \mathrm{ml}$ water and $6 \mathrm{ml}$ of FRAP reagent.

Blank: $0.8 \mathrm{ml}$ water mixed with $6 \mathrm{ml}$ of FRAP reagent.

After 5 minutes the samples were read at $593 \mathrm{~nm}$. There were made 3 determinations and at every determination were made 3 repeated readings. The results are the average of the 3 determinations.

A trolox calibration curve was built in same condition using 10 to 40 $\mu \mathrm{g}$ of trolox.

\section{Antioxidant capacity determination by NO radical inhibition method [23]}

Samples: $0.50 \mathrm{ml}$ of each extract is mixed with $3 \mathrm{ml} 10 \mathrm{mM}$ sodium nitroprusside in $0.2 \mathrm{mM}$ phosphate buffer at $\mathrm{pH}$ of 7.4. These mixtures were maintained at $30^{\circ} \mathrm{C} 150$ minutes. Than is added $0.5 \mathrm{ml}$ Griess reagent.

Control: $0.50 \mathrm{ml}$ of solvent used for extraction is mixed with $3 \mathrm{ml} 10$ $\mathrm{mM}$ sodium nitroprusside in $0.2 \mathrm{mM}$ phosphate buffer at $\mathrm{pH}$ of 7.4 . These mixtures were maintained at $30^{\circ} \mathrm{C} 150$ minutes. Than is added $0.5 \mathrm{ml}$ Griess reagent.

Blank: $3 \mathrm{ml}$ of $0.2 \mathrm{mM}$ phosphate buffer at $\mathrm{pH}$ of 7.4 with $0.5 \mathrm{ml}$ extract were maintained at $30^{\circ} \mathrm{C} 150$ minutes. Than is added $0.5 \mathrm{ml}$ Griess reagent.

The samples were read at $546 \mathrm{~nm}$. There were made 3 determinations and at every determination were made 3 repeated readings. The results are the average of the 3 determinations.

For each sample was determined the inhibition percentage using the following formula:

$$
1 \%=\left(A_{\text {control }}-A_{\text {sample }}\right)^{* 100 / A_{\text {control }}}
$$




\section{Experimental Conditions for TLC Separation [19]}

The separations were performed on silicagel plates. As standards were used methanolic solutions of: hyperoside $(1.00 \mathrm{mg} / \mathrm{mL})$ and caffeic acid $(1.00$ $\mathrm{mg} / \mathrm{mL}$ ). On plates were applied $20 \mu \mathrm{L}$ from tinctures and $30 \mu \mathrm{l}$ from solution obtained after SPE separation of glycerol [24] from young shoots extract respectively $10 \mu \mathrm{L}$ from each standard solution. The samples and standard solutions were applied as bands of $2 \mathrm{~cm}$. The plates were developed ascendant in normal chamber. The mobile phase was: ethyl acetate - ethylmethyl ketone - water - formic acid (50:30:10:10, v/v) and development distance was $10 \mathrm{~cm}$. After drying of plate it was sprayed with diphenylboric acid aminoethyl ester $1 \%$ in methanol and PEG-400 $5 \%$ in methanol. The plate was visualized after 30 minutes in fluorescence, at $365 \mathrm{~nm}$.

\section{Experimental Conditions for HPLC Separation [25]}

The separations were performed on Sil-C18 column. As standards were used methanolic solutions of: vitexine $(40-320 \mu \mathrm{g} / \mathrm{mL})$, chlorogenic acid $(0.1 \mathrm{mg} / \mathrm{ml})$ and rutoside $(1.11 \mathrm{mg} / \mathrm{mL})$. The mobile phase is presented in table 5 . It was used $1 \mathrm{ml} / \mathrm{min}$ flow rate and a DAD UV-Vis detector at 280 $\mathrm{nm}$. There were injected $10 \mu \mathrm{l}$ from each sample and standard solution. Each extract was diluted 1 to 10 with methanol prior injection and filtered through $0.45 \mu \mathrm{m}$ Teflon filter.

Table 5. The mobile phase composition for HPLC separation

\begin{tabular}{|c|c|c|c|}
\hline Time, min & $\begin{array}{c}\text { Water - phosphoric } \\
\text { acid, } \mathrm{pH}=2.5\end{array}$ & Methanol & Acetonitrile \\
\hline 0 & 75 & 10 & 15 \\
\hline 30 & 75 & 10 & 15 \\
\hline 35 & 69 & 12 & 19 \\
\hline 40 & 67 & 12 & 21 \\
\hline 60 & 54 & 15 & 81 \\
\hline
\end{tabular}

\section{REFERENCES}

1. *** "European Pharmacopoeia", $9^{\text {th }}$ edition, EDQM, 2017.

2. *** "French Pharmacopoeia", 11 $1^{\text {th }}$ edition, ANSM, 2007.

3. I.E. Orhan, Current Medicinal Chemistry, 2016, 23.

4. A. Karioti, E. Giocaliere, C. Guccione, G. Pieraccini, E. Gallo, A. Vannacci, A.R. Bilia, Journal of Pharmaceutical and Biomedical Analysis, 2014, 88, 7. 
5. J. Wang, X. Xiong, B. Feng, Evidence Based Complementary and Alternative Medicine, 2013, 2013.

6. P. Ficarra, R. Ficarra, A. de Pasquale, M.T. Monforte, M.L. Calabro, Farmaco, 1990, 45(2), 247.

7. Y. Benmalek, O.A. Yahia, A. Belkebir, M.L. Fardeau, Bioengineered, 2013, 4(4), 244.

8. A.R. Bilia, F. Eterno, M.C. Bergonzi, G. Mazzi, F.F. Vinceri, Journal of Pharmaceutical and Biomedical Analysis, 2007, 44(1), 70.

9. A. Mumtaz, M. Sultan, R.S. Muhammad, K. Ajmal, R. Umer, F. Umar, U. Farhat, S. Abdul, A. Muhammad, A. Majid, A. Manzoor, L. Abdul, Frontiers in Pharmacology, 2017, 8, 327.

10. I.E. Orhan, A. Gokbulut, F.S. Senol, Current Pharmaceutical Design, 2017, 23(7), 1051.

11. M. Akila, H. Devaraj, Vascular Pharmacology, 2008, 49(4-6), 173.

12. V.M. Tadic, S. Dobric, G.M. Markovic, S.M. Dordevic, I.A. Arsic, N.R. Menkovic, T. Stevic, Journal of Agricultural and Food Chemistry, 2008, 56(17), 7700.

13. S. Rastogi, M.M. Pandey, A.K. Rawat, Phytomedicine, 2016, 23(11), 1082.

14. H. Alp, B.C. Soner, T. Baysal, A.S. Sahin, Anatolian Journal of Cardiology, 2016, 15(12), 970.

15. J.M. Rigelsky, B.V. Sweet, American Journal of Health System Pharmacy, 2002, 59(5), 417.

16. Lacaille-Dubois, U. Franck, H. Wagner, Phytomedicine, 2001, 8(1), 47.

17. L. Jalaly, G. Sharifi, M. Faramarzi, A. Nematollahi, M. Rafieian-Kopaei, M. Amiri, F. Moattar, Daru, 2015, 23, 54.

18. F.H. Degenring, A. Suter, M. Weber, R. Saller, Phytomedicine, 2003, 10(5), 363.

19. *** "German Homeopathic Pharmacopoeia", ed. 2016, MedPharm Scientific Publishers, 2016.

20. *** "Farmacopeea Română", ed. X, Editura Medicală, București, 1993.

21. *** "Farmacopeea Română", ed. IX, Editura Medicală, București, 1976.

22. K. Thaipong, U. Boonprakob, K. Crosby, L. Cisneros-Zevallos, D. Hawkins Byrne, Journal of Food Composition and Analysis, 2006, 19, 669.

23. M.N. Alam, N.J. Bristi, M. Rafiquzzaman, Saudi Pharmaceutical Journal, 2013, 21, 143.

24. S. Cobzac, G. Cimpan, N. Olah, S. Gocan, Journal of Planar Chromatography - Modern TLC, 1999, 12(1), 26.

25. A. Dărăban, N.K.Olah, R.F. Câmpean, F. Furtuna, C. Cobzac, Gh. Dehelean, M. Bojiță, D. Hanganu, Studia UBB Chemia, 2015, 60 (2), 125. 